\title{
Malaysian Children Storybooks as ESL Reading Materials
}

\author{
Adlina Ismail ${ }^{1 *}$, Normah Yusof ${ }^{2}$ \\ ${ }^{1}$ University College Bestari, 22100, Terengganu, Malaysia \\ ${ }^{2}$ Universiti Sultan Zainal Abidin, 21300, Terengganu, Malaysia
}

Corresponding author: Adlina Ismail, E-mail: adlina@ucbestari.edu.my

\section{ARTICLE INFO}

Article history

Received: January 31, 2018

Accepted: June 06, 2018

Published: July 31, 2018

Volume: 6 Issue: 3

Conflicts of interest: None

Funding: None

\begin{abstract}
English as a Second Language (ESL) reading materials for children are important in second language development. It is believed that language cannot be taught in a vacuum context as language functions within a culture. Even though learning a language requires learning about the culture unconsciously, learners' culture should be taken into consideration as well. The study aimed to identify the difference between Malaysian picture storybooks and Malaysian chapter storybooks in terms of readability by using a computational tool, Coh-Metrix TERA. This study also aimed to discuss the suitability of the samples' readability in relation to the second language comprehension and cognitive development theories. The study collected 10 locally published picture storybooks and chapter storybooks each. The narrative texts from the books were extracted and assessed by CohMetrix TERA. It was found that picture storybooks are different from chapter storybooks in terms of the amount of concrete words, referential cohesion devices, and familiar words in the texts. In general, the samples' readability is in line with the cognitive development theory. However, they can be improved in terms of cohesive devices and familiar words. In brief, Malaysian picture storybooks and chapter storybooks are suitable to be used as reading materials to learn English for Malaysian children. Nevertheless, weak readers may require adult assistance in certain parts of the books.
\end{abstract}

Keywords: Readability, Reading Materials, ESL Learning, Young Learners, Storybooks, Linguistic Factors

\section{INTRODUCTION}

Reading is one of the four skills which are necessary in order to learn a language. Unlike speaking and listening skills, reading and writing skills are known as literacy skills. This is because while humans acquire (first) language (speaking and listening skills) naturally as a part of their natural instinct, literacy skills need to be taught (Moats \& Tolman, 2009). Humans have to learn the writing system of the language to be able to read and write in the language. In learning English as a Second Language, reading skill is important for learners to increase their language input for their environment might not use spoken English as widely as in native countries. Moreover, Sadiku (2015) also believes that reading offers a productive approach to improving language especially in vocabulary and word power. Consequently, English reading materials are used extensively in the early language development.

While reading materials from foreign countries such as the United States and the United Kingdom have flooded the Malaysian market, local reading materials should not be ignored. These materials offer different aesthetic, social and educational experiences (Nikolejeva, 2003). After the independence, the Malaysian government encouraged Malaysian writers to produce works that portray a conscious Malay- sian cultural background to help nation building (Kassim, Fernandez, and Mohd Khir, 2010). Moreover, local English reading materials for children are important to teach nation's values to children by helping them to learn English in the Malaysian context as opposed to foreign context and values in the imported books.

However, Arbaie Sujud (2011 as cited in Ariffin, 2011) brought up the issue of local books' quality. He mentioned that children and young people today are less fond of the local works (children literature and youth literature) because the stories were difficult to understand and they do not meet their needs. This has resulted in locally published children literature and youth literature are unable to perform their functions as a source of entertainment and education.

He further explained that local works can be improved by making sure the language use is suitable to the target readers because unmatched language level might deter readers' comprehension. Abdullah and Hashim (2007) and Mohamed Isa (2009) argue that unsuitable books may discourage reading activity. Despite this critique, there is a very limited number of studies conducted on children books in Malaysia in terms of their content and language use (Chew \& Ishak, 2010). Therefore, improvements are difficult to be made in order to produce children books of better quality. 


\section{Objective and Research Questions}

This article has two purposes. Firstly, it aimed to compare the readability of local picture storybooks and local chapter storybooks. Secondly, from the identified differences, this article discusses the suitability of the samples as reading materials according to second language development and cognitive development theories. Two research questions were developed which are;

1. How are local picture storybooks different from chapter storybooks in terms of readability?

2. Are local picture storybooks and chapter storybooks suitable to be used as ESL reading materials?

\section{LITERATURE REVIEW}

\section{Storybooks as Language Learning Materials}

As much as textbooks are widely used in language teaching classes, textbooks alone are not enough to improve language competency. Leisure reading or extensive reading is beneficial to learners, whether it is in linguistic aspects or even in non-linguistic aspects. By reading a lot of materials by choice, readers can enhance general language competence, extend and sustain vocabulary growth, improves writing skills, expand world knowledge, creates and sustain motivation to read and develop learner autonomy (Maley, 2009).

Storybooks are related very closely to extensive reading because these books are generally picked up by children to be read for entertainment. Children are attracted to storybooks for many reasons. The narrative nature of the storybooks is the main attraction of this genre. According to Ayob (1981), it is easier for children to understand ideas and information through stories where they will be able to connect the ideas better comparing to informative text. A story would allow children to feel, think, and experience. Another contributing factor to the attraction is the pictures in the storybooks. Children fictions tend to have a lot of pictures to compensate for the simpler language used. These pictures which are related to the text, serve as an aid for the children to understand the meaning and context of the story. They help in retaining children's attention and the big colorful pictures would surely intrigue children's interest. Even young readers of older age group appreciate several pictures incorporated in books. As mentioned by Hamid and Hassan (2012), children have a tendency to like creative and imaginative element in a reading material. Moreover, Hsieh, Wang, and Lee (2011) also pointed out in their study that storybooks provided far more exposure to vocabulary compared to textbooks. Texts in fiction books can be read comfortably and are able to contribute to learners' fluency development (Hill, 2008).

It is also crucial to choose suitable storybooks or reading materials for children. According to Deweerdt (2001), a recommended course of reading material for young children should incorporate a roughly equal balance of four main aspects; meaning-focused input, language-focused learning, meaning focused output and fluency development. A good meaning-focused input refers to language usage that the learners are exposed to. The language should contain language features (vocabulary and sentence structure) that can be comprehended by the learners with a few features that are beyond the learners' knowledge. Krashen (1982) also pointed out the importance of suitable input in his Comprehensible Input theory. The input should contain " $i$ " (what the learners already knew) and " +1 " (what learners have not learned) to allow language acquisition happens successfully. It is believed that learners will not able to gain anything if the input (reading materials in this case) is too difficult and cannot be comprehended by learners or if the input is too easy.

\section{Local Reading Materials as ESL Reading Materials}

Language functions within a culture. Therefore, it is impossible to teach language separately from culture (Rowsell et al., 2007). Even though the popular belief is that second language is best learnt within the context of the target language's culture, this is not entirely true. English materials which based on the target language's culture (the United Kingdom or the United States) might pose unnecessary difficulty to the young learners. Young learners naturally have limited world-knowledge. Hence, this will burden them to deal with not only unfamiliar language, but also unfamiliar topics or culture (Zohrabi \& Mohd Shah, 2009). The factors of social and cultural differences can affect the learners' ability to comprehend the materials (Grabe, 2014).

Therefore, in language teaching, it is important to regard learners' cultural background (Choundhury, 2014). The language learnt needs to be associated with the leaner's cultural background for the language teaching to be successful. This will provide a platform for the practicality of the language being learnt as the learners can connect the language learnt to their daily lives. Local culture based materials may hold the answer to this problem. Learners will be able to learn English in Malaysian context as opposed to foreign context and values in the imported books. Abdullah and Hashim (2007) also mentioned that local materials can be the way to penetrate into more complex texts for less skilled readers such as young readers. Therefore, it is recommended to introduce beginners to ESL materials which based on the learners' local culture elements.

\section{Cognitive Development and Second Language Comprehension Theories}

Reading comprehension is the process of making meaning from text. The goal is to gain an overall understanding of what is described in the text rather than to obtain meaning from isolated words or sentences (Woolley, 2011). Cognitively based views of reading comprehension emphasize the interactive nature of reading and the constructive nature of comprehension (Wang \& Gafurov, 2010). Moreover, the differences in the cognitive process, background knowledge, language competency, culture differences and fluency between L1 and L2 may also affect reading comprehension.

Cognitive theory emphasizes on mental processes rather than observable behavior. According to this theory, knowledge is seen as something that is actively constructed by learners based on their existing cognitive structures. Therefore, learning is relative to their stage of cognitive devel- 
opment and understanding the learner's existing intellectual framework is central to understanding the learning process. As we are discussing reading materials for young readers, it is appropriate to brief on Piaget's theory of children's cognitive development. In Piaget's Cognitive Development theory, he proposed four stages of cognitive development for children. The stages are known as 1) sensorimotor, 2) preoperational, 3) concrete operational, and 4) formal operational (Wood, Smith, \& Grossriklaus, 2001). A human starts with the sensorimotor stage when they are still infants. It is their first contact with a language. Children usually start reading in the preoperational stage. At this stage, they are attracted to pictures because they start to understand pictures as a part of stories. Therefore, picture storybooks are suitable for children at this stage. In the concrete operational stage, children will be able to make logic connections and solve problems. They are also able to read chapter storybooks because they can continue the story after stopping for a short while. In the formal operational stage, children are able to form hypotheses and solve abstract problems (Mohamed Isa, 2009).

Other than the cognitive development stages, word concreteness should also be considered because the concreteness of an idea influences children's mental lexicon. Therefore, children generally acquire concrete words earlier and also comprehend concrete words faster than abstract words (Crossley, Salsbury, McNamara, \& Jarvis, 2010; Caramelli, Setti, \& Maurizzi, 2004). Similar to concrete words, familiar words are learned, recognized and memorized by children faster than unfamiliar words because they learn the names of those things that they are most often exposed to faster (Rafi, 2013) and familiar topics which are closer to the readers can help comprehension (Choundhury, 2014). In addition, the lack of cohesion in a text may produce 'gaps'. 'Gaps' will exist in a text when the content words do not connect or relate to the surrounding sentences and they can only be filled by making inferences (McNamara, Graesser, McCarthy, \& Cai, 2014). However, according to Schwanenflugel and Knapp (2015), children are weak in making inferences. This is due to two reasons; they often lack the prior knowledge upon which such inferences would be based and they may not have the skills to retrieve relevant information from prior knowledge even when they possess it.

In terms of L2 reading comprehension, Grabe (2014) listed a few differences between L1 and L2 reading. First, L2 readers have a smaller L2 linguistic knowledge base, especially at the early stage (children and teenagers). Their knowledge of vocabulary, grammar, and discourse structure is more limited. This is due to the different timelines by which L1 and L2 are acquired. L1 acquisition begins at infancy, so L1 learners have mastered most primary grammar structures before their formal education starts. L2 learners, however, are still in the process of acquiring the grammar when they start reading in L2 (Heilman, Collins-Thompson, Callon, \& Eskenazi, 2007). Second, L2 readers are generally less exposed to L2 compared to L1. Thus, they will have less practice in L2 reading. Third, L2 readers cognitive processing will involve two languages system (mother tongue and L2) during the reading process. Fourth, L2 readers will expe- rience a range of transfer effects from their L1 unconsciously and this can either interfere or facilitate L2 comprehension. It depends on how similar reader's L1 language structure to L2. The more L1 is similar to L2, the higher the possibility that it will help L2 comprehension. The fifth and sixth differences are related to background knowledge or differences in "how the world works". It is about social and cultural assumptions. In most cases, knowledge gaps could exist because of the different culture between the authors and the readers.

Hence, it is essential for ESL reading materials to be developed in parallel to cognitive development and second language comprehension theories. Chew, Arshad, Ishak, and Cheong (2008) supported this idea by mentioning that the writing style of a book should be suitable to the age, mindset, and language competence of the readers. It is because their cognitive ability affects their reading comprehension and unsuitable reading materials might pose unnecessary difficulties for the children. Furthermore, reading in L2 is different from reading in L1 and different factors may affect L2 reading comprehension to a different extent than L1.

\section{The Measurement of Readability}

Dale and Chall (1949) defined readability as the sum of elements in a reading text which contribute to the comprehension, speed, and interest as seen by the readers. It is almost impossible to achieve an agreement on how to measure readability due to the various opinions and theories proposed in related to readability. For example, Abdullah and Hashim (2007) believed that readability is constructed of three factors which are external text (font size, font type, and illustration), reader (ability, motivation, and schema) and text's linguistic aspect (vocabulary, syntax, conceptual difficulty and textual structure). On the other hand, DuBay (2004) introduced four basic elements of reading ease (readability); content, style, structure, and design. Benjamin (2011) claimed that text difficulty and readability were more related to coherence and the relationship between elements in a text rather than simply the sum or averages of individual surface features. Integrating readers, theme, and legibility aspects of readability assessments seem reasonable if we stand under the notion that reading is an interactive activity between readers and texts. However, it may be difficult to measure knowledge, motivation, and legibility because not all of them are quantifiable (Kasule, 2011). Moreover, aspects related to readers such as language competence, interest, and background knowledge are unique according to each individual. Hence, most readability studies had to separate reader aspects from the measurement of the text readability, and match the text to the readers in another process.

Word length and sentence length or variations of on these construct have been the key factors in readability measurement (Chall \& Dale, 1995) because it is believed that reading difficulty is positively correlated with longer sentences and multi-syllable words (Rollins \& Lewis, 2013). Sentences with more words are deemed more complex than a sentence with lesser words. Some of the popular formulas that calculate readability based on this theory are the Gunning Fog 
Index, the Fry Readability Graph, and the Flesch-Kincaid Readability Formula. While this notion is not wrong, it is not entirely true as well. After years of developments in psychology, corpus linguistics, and discourse processing disciplines, these readability formulas are seen as a shallow assumption which only analyzes limited features of textual context (McCarthy, Lewis, Dufty, \& McNamara (2006). Not all short sentences are easy and vice versa. These formulas are unable to consider deeper levels of text processing, cohesion, rhetorical organization, and prepositional density (Heilman et al., 2007; McNamara \& Greasser, 2012; McNamara, Graesser, McCarthy, \& Cai, 2014).

While the human-based evaluation method is considered as the most reliable and comprehensive, it highly depends on the raters' intuitions which are influenced by their skills and personal experience. Besides, large-scale human evaluation requires large resources in terms of time and human power. There is also no guarantee of the consistency of how the text is evaluated (Graesser, McNamara, \& Kulikowich, 2011). Moreover, methods grounding on intuition may not be very useful in attempts to provide empirical evidence for the quantifiable qualities of a text.

For the mentioned reasons, this study would like to put forward Coh-Metrix TERA as an alternative to measure text readability. Coh-Metrix TERA, also known as Coh Metrix Common Core Text Ease and Readability Assessor is developed by the University of Memphis and Arizona State University based on psychology theory of comprehension. This theory explains that there are a few stages of comprehension, different text features contribute $t$ different stage of comprehension, and different stage of comprehension requires different cognitive process (Graesser, McNamara, Louwerse, \& Cai, 2004). Graesser and McNamara (2011) specifically mentioned five levels of discourse which related to readability. From the surface to the deeper level, they are words, syntax, explicit textbase, referential situation model, and genre and rhetorical structure. Coh-Metrix TERA is a version of Coh-Metrix which offers 40-80 validated indices to measure text. Coh-Metrix TERA was developed after comprehensive studies were conducted (McNamara, Graesser, Cai, \& Kulikowich, 2011; Graesser et al., 2011) on correlating Coh-Metrix indices with graded texts by DRP level. The indices which were found to be are accountable for the majority of the DRP level variance and closely aligned to the five-level theoretical model were gathered together in Coh-Matrix TERA. The indices are word concreteness, syntactic simplicity, referential cohesion, deep cohesion, and narrativity. These indices provide insight into the multilevel of comprehension (Ismail, Yusof, \& Yunus, 2016).

Unlike other readability formulas, Coh-Metrix TERA does not overgeneralize readability. Texts in the same level of difficulty can have different text (linguistic) characteristics (Szabó, 2014; Heibert, 2012). There is a possibility that two texts with different sources of difficulty are considered as the same level of difficulty. Similarly, readers at the same level might be affected by different text features. Most readability formulas disregard these important differences. However, Coh-Metrix TERA does not represent readability as a single numeric score but in five ease scores (indices). This allows us to identify the source of difficulty or the source of ease in readability of a text and compare the texts. This will be very useful for educators and researchers who wish to analyze and discuss reading texts in deeper view.

\section{METHODOLOGY}

\section{Samples}

The samples collected in this study were ten locally published picture storybooks and ten locally published chapter storybooks. They were collected using purposive sampling method and the collection process was verified by three subject matter experts. These two types of storybooks were chosen as the samples of the study because the categorization of other local storybooks is vague. It will be difficult to collect relevant samples. Moreover, these two storybooks are representative of children development stages; picture storybooks are suitable for preoperational stage and chapter storybooks are suitable for the concrete operational stage (Mohamed Isa, 2009).

In this study, picture storybooks refer to children books with story plots and the pictures dominate the content. Usually, the pictures take up $50 \%$ to $75 \%$ of the pages and they are representative of the story. Meanwhile, chapter storybooks may contain pictures, but it is not mandatory. A chapter storybook has only one story plot but it is divided into a few short chapters. All of the samples were published by Malaysian publisher companies.

\section{Procedure of Data Analysis}

After the samples had been collected, the samples were verified by three qualified raters to make sure that they belong to their respective categories. If any of the samples were rejected by the raters, they will be excluded from the study and new samples will be chosen. After 10 picture books and 10 chapter books were collected, they were converted from hard copy books into softcopy format (.txt) which can be analyzed by Coh-Metrix TERA (McNamara et al., 2013). This was achieved by using OCR scanner software. Finally, ease scores for each of the samples were generated by Coh-Metrix TERA.

\section{Coh-Metrix TERA}

Coh-Metrix TERA offers five indices which are word concreteness, syntactic simplicity, Deep Cohesion, Referential Cohesion, and finally narrativity. The five variables of Coh-Metrix TERA were derived from the previous extended studies (McNamara et. al, 2011; Graesser et al., 2011). Unlike other readability measurements, Coh-Metrix TERA measures the easiness of the text rather than the difficulty. A low score in certain indices means that there are difficulties at the levels of comprehension represented by the indices. Coh-Metrix TERA counts concrete words as opposed to abstract words in word concreteness index. Syntactic simplicity was determined by word count, clause count, 
sentence count, and sentence structure. Other than containing simple sentence structure, text with similar sentence structures also is considered easy. Referential cohesion index calculates co-lexical cohesion devices such as nouns overlaps, pronouns overlaps, and argument overlaps. Word overlaps are able to aid in text comprehension and reading speed which both are helpful for young readers (Crossley, McCarthy, Louwerse, \& McNamara, 2007). Deep cohesion index refers to the explicit particles such as connectives, adverbs, and signal words. These particles function to tie the text together in a coherent manner. Lastly, Narrativity index measures the extent to which a text is classified as opposed to informational text and familiar words are believed to be closely related to narrativity (Graesser et al., 2011).

\section{RESULTS AND DISCUSSION}

\section{The Differences between Picture Storybooks and Chapter Storybooks}

Coh-Metrix TERA measures a text's readability according to five indices; word concreteness, syntactic simplicity, referential cohesion, deep cohesion, and narrativity. Each index has the maximum score of 100 and the minimum score of 0 . Furthermore, the system categorized result below 25 as low, above 75 as high and in between as average.

After all of the samples were analyzed by Coh-Metrix TERA, the result shows that the majority $(80 \%)$ of the selected picture storybooks scored high in word concreteness, while the majority $(70 \%)$ of chapter storybooks only scored average in the same index. Concrete words help young readers in comprehending the texts because they are easier to be imagined compared to abstract words. This is supported by previous research which found that words with high imageability are easier to be retrieved by the mind (De Groot, 1989) and concrete words as less difficult (Johnson \& Bruning, 1984). Concrete words offer more characteristics which can be represented by our mind. Thus, they can be remembered and retrieved by readers easier. Moreover, these concrete words are also easy to be represented as images in the picture storybooks. These visual properties not only caught readers' attention, but they are also able to aid comprehension (Sadiku, 2015).

In syntactic simplicity, all samples from both categories were found to score high. This indicates that both the selected picture storybooks and chapter storybooks were written in easy sentence structures. These findings support Heilman et al. (2007) in that the length of sentences or text does not represent the sentence complexity. Even though all of the chapter storybook samples are prominently longer than picture storybooks samples, they were found to be easy in syntactic simplicity. The is because Coh-Metrix TERA measures text simplicity based on word count, clause count, sentence count, and sentence structure. Other than containing simple sentence structure, text with similar sentence structures also is considered easy in syntactic simplicity index (Crossley. Allen, \& McNamara, 2011).

The majority $(70 \%)$ of picture storybooks shows average scores, two show high scores and only one was low in ref- erential cohesion. Meanwhile, chapter storybooks have an equal number of books $(50 \%)$ that show average and low scores in referential cohesion. None of them scored high. This shows that more picture storybooks make use of referential cohesion devices such as repetition and pronouns in their texts compared to chapter storybooks. This result is unexpected considering chapter storybooks are more extended and contains more events than picture storybooks. As tested by Gernsbacher (1997), referential cohesion allows readers to comprehend and remember the texts in their entirety which is advantageous in reading extended texts. In the present study, chapter storybook samples appear to be quite difficult for the readers as they lack referential cohesion.

In deep cohesion index, the majority of picture storybooks $(80 \%)$ and chapter storybooks $(90 \%)$ scored average and the rest of the samples scored high. This means that both picture storybooks and chapter storybooks contain a similar amount of connecting devices like transition words and conjunctions. These connectors help in establishing deep cohesion (McNamara et al., 2014). Similar to the referential cohesion index, both of picture storybook and chapter storybook samples do not include a lot of discourse markers in their texts. This can pose difficulties for readers as the signals (discourse markers) to map the incoming information may be missing.

Lastly, $60 \%$ of picture storybooks are high in narrativity and $90 \%$ of chapter storybooks show the same result. Other samples scored average in the index. Even though the difference is small, more chapter storybooks were written based on familiar topics and using a high number of familiar words. This is a positive indicator as Grundvig (2012) found in his study that prior knowledge helps and motivates weak readers when they are reading familiar texts. Chapter storybook samples are more challenging because they lack cohesion cues. However, by presenting familiar topics and contents, it motivates readers to read and comprehend the texts (Table 1).

In sum, picture storybooks are different from chapter storybooks in terms of the amount of concrete words, referential cohesion devices, and familiar words in the texts. While more picture storybooks contained many concrete words and repetitions or pronouns, more chapter storybooks presented familiar topics.

\section{The Suitability of Picture Storybooks and Chapter Storybooks as ESL Reading Materials}

This study found that majority of picture storybook samples consists of a high number of concrete words. Meanwhile, most chapter storybook samples show an average number of concrete words. Despite that, it was believed that this will not be a major difficulty for chapter storybook readers. It was proven that children's abstract words (vocabulary) will increase as they aged (Crossley, Salsbury, McNamara, \& Jarvis, 2010). It is because children in the concrete operational stage understand abstract concept better than children in the preoperational stage (Wood, Smith, \& Grossriklaus, 2001). The result supports the findings by Crossley, McCarthy, Louwerse, \& McNamara (2007) and McNamara et al. (2011) which reported that reading materials for older children contain less concrete words. 
Table 1. The Result of Coh-metrix TERA for picture storybooks and chapter storybooks samples

\begin{tabular}{|c|c|c|c|c|c|c|}
\hline \multirow[t]{2}{*}{ Level index } & \multicolumn{3}{|c|}{ Picture storybooks } & \multicolumn{3}{|c|}{ Chapter storybooks } \\
\hline & High & Average & Low & High & Average & Low \\
\hline Word concreteness & 8 & 2 & - & 2 & 7 & 1 \\
\hline Syntactic simplicity & 10 & - & - & 10 & - & - \\
\hline Referential cohesion & 2 & 7 & 1 & - & 5 & 5 \\
\hline Deep cohesion & 2 & 8 & - & 1 & 9 & - \\
\hline Narrativity & 6 & 4 & - & 9 & 1 & - \\
\hline
\end{tabular}

All samples of picture storybooks and chapter storybooks were easy in terms of sentence structure. Easy sentence structures are preferable for beginner learners because these sentences place lower cognitive demands on the reader, so readers can pay more attention to the meanings (Crossley, Allen, \& McNamara, 2011). Even though chapter books are intended for older children compared to picture storybooks, these readers might not able to perform well with difficult sentence structure. This is because these children are still in the process of acquiring L2 grammar and are not familiar with L2 grammar. Thus, it is reasonable that both picture storybooks and chapter storybooks contain easy sentence structures.

Even though the majority of picture storybook samples were only average in referential cohesion according to Coh-Metrix TERA, it needs to be mentioned that pictures in picture storybooks also construct meanings alongside the texts and contribute to the cohesion of the text (Jalongo, 2004; Nicholas, 2007). This can be done especially in the representation of the characters in the picture. Children in the preoperational stage are able to connect images to the text as a part of the story. On the other hand, low referential cohesion in chapter storybooks cannot be compensated by pictures. This might pose a challenge for the readers to comprehend the storybooks because according to Schwanenflugel and Knapp (2015), children are generally weak in making inferences. However, McNamara, Crossley, and McCarthy (2010) mentioned that skillful readers may successfully generate inferences and this will improve comprehension as the new information is connected to the prior knowledge.

According to Bilki (2014), the existence of discourse markers is important for readers who are weak in using their domain knowledge to fill the gaps such as children. According to the result of the study, the majority of the picture storybook and chapter storybook samples contained an average number of discourse markers. This might have contributed to the high scores in the syntactic simplicity index because short sentences are considered simpler than longer sentences. However, the lack of discourse markers can be a source of difficulty for young children to understand the text as 'gaps' exist.

Narrativity can compensate for the difficulty in other indices such as word concreteness, and deep cohesion (McNamara et al., 2014). It is because even though a text scored low in word concreteness (there are a lot of abstract words), being high in narrativity index means that the abstract words are familiar words. The result showed that most of the samples are high in narrativity which means they contain familiar words and discuss on familiar topics. Nonetheless, it is intriguing to see that more picture storybook samples $(90 \%)$ have high narrativity than chapter storybooks $(40 \%)$ even though picture storybooks are targeted for younger children who have more limited world knowledge generally.

\section{CONCLUSION}

As a conclusion, picture storybooks are different from chapter storybooks in terms of the amount of concrete words, referential cohesion devices, and familiar words in the texts. In general, the samples can be used for the intended readers but they might need help in certain parts especially in generating inferences (due to the lack of referential and deep cohesion) and unfamiliar words. This study provides insight into ESL materials for children in Malaysia. Locally produced ESL materials are beneficial in second language development of young learners. They present ideas and cultural elements which are close to the learners. Creative reading materials such as storybooks are also an important source of second language acquisition and learning. Reading of such reading materials allows learning to happen in a low anxiety situation. Both picture storybook and chapter storybook were found to be lacking in cohesion even though cohesion is important for young learners. Reading materials developers such as publishers, writers, and editors may improve their works by paying more attention to the cohesion elements.

The findings of this study only serve as a basis for readability study of local reading materials such as storybooks using a computational tool, Coh-Metrix TERA. They cannot be generalized for the bigger population because of the small sample size and the only types of children storybooks included in this study were picture storybooks and chapter storybooks. In reality, there are more types of children reading materials such as picture books, easy readers, rebus books, and big books. Besides that, this study solely analyzes the text (linguistic) without taking into accounts other possible readability aspects such as legibility and readers. Future research should be conducted by integrating linguistics and readers' aspects into the analysis.

\section{REFERENCES}

Abdullah, I. H., \& Hashim, R. S. (2007). Readability of Malaysian short stories in English. E-Bangi Journal of Social Science and Humanities, 2(2), 1-11. Retrieved from $\mathrm{http}: / /$ www.ukm.my/e-bangi/index.php?option=com 
Ariffin, L. (2011, December 5). Kemelut sastera kanakkanak, remaja di Malaysia. Berita Harian: Ruang Sastera.

Ayob, S. (1981). Sastera untuk kanak-kanak: Fungsi dan implikasinya. Pendidik dan Pendidikan, 3(1), 73-82.

Benjamin, R. G. (2011). Reconstructing readability: Recent developments and recommendations in the analysis of text difficulty. Educational Psychology Review, 24(1), 63-88. Retrieved from http://link.springer.com/article/10.1007\%2Fs10648-011-9181-8\#page-1.

Bilki, Z. (2014). A close observation of second language (L2) readers and texts: Meaning representation and construction through cohesion (Doctoral dissertation). University of Iowa, Iowa, United States.

Caramelli, N., Setti, A., \& Maurizzi, D. D. (2004). Concrete and abstract concepts in school age children. Psychology of Language and Communication, 8(2), 19-34.

Chew, F. P., Arshad, M., Ishak, Z., \& Cheong, L.S. (2008). Pendidikan kesusasteraan awal kanak-kanak: Isu dan masalah. Masalah Pendidikan, 31(1), 77-89.

Chew, F. P., \& Ishak, Z. (2010). Malaysian folk literature in early childhood education. World Academy of Science, Engineering and Technology, 66, 557-564. http://www.sciencedirect.com/science/article/pii/ S1877050913012209

Chall, J. S., \& Dale, E. (1995). Readability revisited. Michigan: Brookline Books.

Choundhury, R. U. (2014). The role of culture in teaching and learning of English as a foreign language. Express, an International Journal of Multi-Disciplinary Research, 1(4), 2348- 2052.

Crossley, S. A., McCarthy, P. M., Louwerse, M. M. \& McNamara, D. S. (2007). A linguistic analysis of simplified and authentic texts. The Modern Language Journal, 91(1), 15-30

Crossley, S. A., Salsbury, T., McNamara, D.S. \& Jarvis, S. (2010). Predicting lexical proficiency in language learner texts using computational indices. Language Testing, 28 (4), 561- 580.doi: 10.1177/0265532210378031. Retrieved from http://ltj.sagepub.com

Crossley, S. A., Allen, D. B., \& McNamara, D. S. (2011). Text readability and intuitive simplification: A comparison of readability formulas. Reading in a Foreign Language, 23(1), 84-101. Retrieved from http://nflrc. hawaii.edu/rfl.

Crossley, S. A., McCarthy, P. M., Louwerse, M. M. \& McNamara, D. S. (2007). A linguistic analysis of simplified and authentic texts. The Modern Language Journal, 91(1), 15-30.

Crossley, S. A., Salsbury, T., McNamara, D.S. \& Jarvis, S. (2010). Predicting lexical proficiency in language learner texts using computational indices. Language Testing, 28(4), 561- 580.doi: 10.1177/0265532210378031. Retrieved from http://ltj.sagepub.com.

Dale, E. \& Chall, J. S. (1949). The concept of readability. Elementary English, 26, 19-26.

De Groot, A. M. (1989). Representational aspects of word imageability and word frequency as assessed through word association. Journal of Experimental Psychology: learning, Meaning and Cognition, 15(5), 824-845.

Deweerdt, J. P. (2001). A defense of simplification. Prospect, 16(3), 55-67.

DuBay, W. H. (2004). The principles of readability. Impact Information. Retrieved fromhttp://www.nald.ca/library/ research/readab/readab.pdf.

Gernsbacher, M. A. (1997). Coherence cues mapping during comprehension. In Costermans, J. \& Fayol, M. (Eds.), Processing interclausal relationships (pp.3-22). New York: Psychology Press.

Grabe, W. (2014). Key Issues in L2 Reading Development. In CELC Symposium Bridging Research and Pedagogy (8-18). Retrieved from http://www.nus.edu.sg/celc/research/symposiumproceedings.php.

Graesser, A. C., McNamara, D. S., Louwerse, M. M., \& Cai, Z. (2004). Coh-metrix: Analysis of text on cohesion and language. Behavior Research Methods, Instruments, \& Computers, 36(2), 193-202.

Graesser, A. C., \& McNamara, D. S. (2011). Computational analyzes of multilevel discourse comprehension. Topics in Cognitive Science, 3, 371-398. Retrieved from http://onlinelibrary.wiley.com/doi/10.1111/j.17568765.2010.01081.x/full.

Graesser, A. C., McNamara, D. S., \& Kulikowich, M. (2011). Coh-Metrix: Providing multilevel analysis of text characteristics. Educational Researcher, 40(5), 223-234. Retrieved from http://er.aera.net.

Grundvig, V. (2012). Can picture books in the English classroom lead to increased reading comprehension? (master's thesis). Ostfold University College, Norway.

Hamid, R., \& Hassan, S. (2012). Penerapan sastera dalam pengajaran bahasa di sekolah rendah. In Seminar $B a-$ hasa Melayu 2012: Kecekapan berbahasa dan penghayatan nilai dalam pendidikan abad ke-21 (pp. 226-234). Singapore: MLCS. Retrieved from https://malaylanguagecentre.moe.edu.sg/images/pdf/16-penerapan-sastera-dalam-pengajaran-bahasa-di-sekolah-rendah-Hamid-Hassan.pdf.

Hiebert, E. H. (2012). Readability and the Common Core's staircase of text complexity. Santa Cruz, CA: Text Project Inc.

Heilman, M. J., Collins-Thompson, K., Callan, J. \& Eskenazi, M. (2007). Combining lexical and grammatical features to improve readability measures for first and second language texts. In Proceedings of NAACL HLT (pp. 460-467). Rochester, NY: Association for Computational Linguistics. Retrieved from http://www.cs.cmu. edu/ callan/Papers/hlt07-mheilman.pdf

Hill, D. R. (2008). Graded readers in English. ELT Journal, 62(2), 184-204. Retrieved from http://eltj.oxfordjournals.org.

Hsieh, M., Wang, F., \& Lee, S. (2011). A corpus-based analysis comparing vocabulary input from storybooks and textbooks. The International Journal of Foreign Language Teaching, 25-33.

Ismail, A., Yusof, N., \& Yunus, K. (2016). The readability of Malaysian English children books: A multilevel 
analysis. International Journal of Applied Linguistics \& English Literature, 5(6), 214-220. Retrieved from http:// www.journals.aiac.org.au/index.php/IJALEL/article/ view/2710/2314

Jalongo, M. R. (2004). Young children and picture books. Washington, DC: National Association for the Education of Young Children.

Johnson, C. W. \& Bruning, R. (1984). Concreteness, imagery, comprehensibility and complexity ratings for technical vocabulary. Psychological Reports, 55(1), 171-179.

Kassim, S. R., Fernandez, S. T. \& Mohd Khir, R. J. (2010). Children's Literature in English: a Malaysian Perspective. Retrieved from http://eprints.um.edu.my/12866/ Children's_Literature_in_English.pdf.

Kasule, D. (2011). Textbook readability and ESL learners. Reading and Writing 2(1), pp. 63-76.

Krashen, S. D. (1982). Principle and practice in second language acquisition. Hayward, CA: Alemany Press.

Maley, A. (2009). Extensive reading: Why it is good for our students... and for us. Teaching English. Retrieved from https://www.teachingenglish.org.uk/article/extensivereading-why-it-good-our-students.

Moats, L, \& Tolman, C (2009). Language Essentials for Teachers of Reading and Spelling (LETRS): The Challenge of Learning to Read (Module 1). Boston: Sopris West.

Mohamed Isa, Z. (2009). Choosing appropriate Bahasa Melayu books for Malaysian children. Jurnal Bitara, 2, 45-57.

McCarthy, P. M., Lewis, A., Dufty, D. F., \& McNamara, D. S. (2006). Analyzing writing styles with Coh-Metrix. In G. C. Sutcliffe \&R.G. Goebel (Eds.), Proceedings of the $19^{\text {th }}$ annual Florida Artificial Intelligence Research Society international conference (pp.764-770). Melbourne Beach, FL: AAAI Press. Retrieved from http://aaaipress.org/Papers/ FLAIRS/2006/Flairs06-151.pdf.

McNamara, D. S., Crossley, S. A., \& McCarthy, P. M. (2010). Linguistic features of writing quality. Written Communication, 27(1), 57-86. doi: 10.1177/0741088309351547. Retrieved from http://wcx.sagepub.com.

McNamara, D. S., Graesser, A. C., Cai, Z., \& Kulikowich, M. (2011). Coh-Metrix easability components: Aligning text difficulty with theories of text comprehension. Paper presented at The Annual Meeting of the American Educational Research Association, New Orleans, LA.

McNamara, D. S., \& Graesser, A. C. (2012). Coh-Metrix: An automated tool for theoretical and applied natural language processing. In P. M. McCarthy \& C. Boonthum (Eds.), Applied natural language processing and content analysis: Identification, investigation, and resolution (pp. 188-205). Hershey, PA: IGI Global.

McNamara, D. S., Graesser, A. C., McCarthy, P. M. \& Cai, Z. (2014). Automated evaluation of text and discourse with Coh-Metrix. New York, NY: Cambridge University Press.
Nicholas, J. L. (2007). An exploration of the impact of picture book illustrations on the comprehension skills and vocabulary development of emergent readers. Unpublished Master thesis, Louisiana State University and Agricultural and Mechanical College, Baton Rouge. Retrieved from etd.lsu.edu/docs/available/etd-03102007072045/unrestricted/jlnicholasdissert.pdf

Nikolejeva, M. (2003). Verbal and visual literacy: The role of picture books in the reading experience of young children. In N. Hall, J. Larson, \& H. Marsh (Eds.), Handbook of Early Childhood Literacy (pp.235-248). London: SAGE Publications Ltd.

Rollins, M. W., \& Lewis, S. D. (2013). A comparison of the readability of newspaper columns written by national journalism award winners. Journal of Organizational Culture, Communications \& Conflict, 17(1), 149-156.

Rafi, M. S. (2013). Natural order of vocabulary acquisition. European Academic Research, 1(5), 721-733. Retrieved from http://euacademic.org/UploadArticle/52.pdf.

Rowsell, J. Sztainbok, V., \& Blaney, J. (2007). Losing strangeness: using culture to mediate ESL teaching. Language, Culture and Curriculum, 20(2), 140-154.

Sadiku, L. M. (2015). The importance of four skills reading, speaking, writing, listening in a lesson hour. European Journal of Language and Literature Studies, 1(1), $29-31$.

Schwanenflugel, P. J., \& Knapp, N. F. (2015). The psychology of reading: Theory and applications. Guilford Publications. Retrieved from https://books.google. com/ books? isbn= 1462523501 .

Szabó, G. (2014). Applying objective measures of text difficulty in the comparison of texts in reading comprehension tasks. In J. Horvath \& P. Medgyes (Eds.), Studies in honour of Marianne Nikolov (pp.385-398). Lingua Franca Csoport. Retrieved from http://books.google.hu/ books?id=pfnjAgAAQBAJ.

Wang, Y., \& Gafurov, D. (2010). The cognitive process of comprehension: A formal description. International Journal of Cognitive Informatics and Natural Intelligence, 4(3), 44-58.

Wood, K. C., Smith, H., Grossniklaus, D. (2001). Piaget's stages of Cognitive Development. In M. Orey (Ed.), Emerging perspectives on learning, teaching, and technology. Retrieved from http://projects.coe.uga.edu/epltt

Woolley, G. (2011). Reading comprehension: Assisting children with learning difficulties. New York: Springer. Retrieved from https://books.google. com.my/books/ about/Reading_Comprehension.html

Zohrabi, M., Mohd Shah, P. (2009, May). Culture-free and culture-bound English language class. Paper presented at the Proceeding of Language and Culture: Creating and Fostering Global Communities, Putrajaya, Malaysia. Retrieved from www.ukm.my/solls09/ Proceeding/PDF/Mohammad\%20Zohrabi\%20\&\%20 Parilah.pdf. 